\title{
Tìm hiểu biến động giá xăng trong mùa COVID-19
}

\author{
Trần Thị Ngọc Mai, Nguyễn Đức Mạnh, Nguyễn Trọng Minh \\ Lê Hồng Thảo My, Đặng Vĩnh Nam
}

Đại học Quốc gia Hà Nội, Hà Nội

Xuân Thủy, Cầu Giấy, Hà Nội

Preprint DOI: $\underline{\text { https://osf.io/ubq26 }}$

\section{ĐặT VẤN ĐỀ}

Covid-19 đang ảnh hưởng rất lớn đến đời sống của con người, khiến cho cuộc sống con người bị đảo lộn và làm ảnh hưởng đến rất nhiều nền kinh tế thế giới. Không nằm ngoài ngoại lệ, xăng cũng là mặt hàng chịu nhiều biến động bất ổn trên thị trường toàn cầu do ảnh hưởng của đại dịch COVID-19 (La, 2020).

Xăng là nguồn năng lượng chủ yếu, là mặt hàng chiến lược, có vai trò quan trọng trong nền kinh tế quốc dân và tham gia vào hầu hết các lĩnh vực: hoạt động sản xuất, giao thông vận tải, thương mại, dịch vụ và đời sống xã hội.(Diệp, 2009)

Xăng là một trong những mặt hàng chịu tác động nhiều nhất từ tình hình Covid 19 trên toàn thế giới. Sự khởi đầu của đại dịch đã dẫn đến sự sụt giảm ban đầu về giá các sản phẩm từ dầu mỏ, và sau đó, giá cũng đột ngột tăng mạnh trở lại khiến thị trường gặp nhiều biến động. Nguyên nhân chính ở đây là do sự bùng phát của một loại virus mới tại Trung Quốc vào cuối năm 2019 và ngay sau đó lan rộng, khiến Tổ chức Y tế Thế giới WHO phải ban bố tình trạng khẩn cấp toàn cầu. Rất nhiều quốc gia, trong đó có Việt Nam phải áp dụng các biện pháp phong tỏa toàn quốc. Chính vì vậy, hoạt động kinh tế toàn cầu trở nên trì trệ, nhu cầu giao thương và đi lại giảm mạnh. Từ đó nhu cầu và giá cả của mặt hàng từ dầu mỏ (tiêu biểu là xăng) cũng sụt giảm nghiêm trọng. Khi dịch bệnh cơ bản được khống chế và các nền kinh tế dần mở cửa trở lại, lượng cung dầu mỏ và các sản phẩm từ dầu mỏ không thể đáp ứng được nguồn cầu quá lớn ngay lập tức, dẫn đến sự tăng giá mạnh của ngành hàng này (Kevin M. Camp, David Mead, Stephen B. Reed, Christopher Sitter, 2021). Trong bài báo cáo ngắn này, chúng tôi trình bày bối cảnh thay đổi (tác động) của giá xăng trong nước và quốc tế trong thời kỳ COVID-19, một số giải pháp chính của chính phủ và quan điểm tiếp cận chung cho vấn đề của chúng tôi. 


\section{BỐI CẢNH}

Năm 2021, khi thế giới dần thích ứng với đại dịch, giá cả xăng trên thị trường quốc tế nói chung và Việt Nam nói riêng đã có nhiều biến động.

\section{Trong nước:}

- Giá bán các loại xăng dầu trong nước áp dụng mức giá bán được điều chỉnh từ 16h chiều 10.11 .

- Theo đó, giá bán các mặt hàng xăng dầu tiêu dùng phổ biến được áp dụng như sau: Xăng E5 RON 92 không cao hơn 23.669 đồng/lít, xăng RON 95-III không cao hơn 24.996 đồng/lít, dầu diesel 0.05S không cao hơn 18.716 đồng/lít, dầu hỏa không cao hơn 17.637 đồng/lít, dầu mazut 180CST 3.5S không cao hơn 16.821 đồng/kg.

- Nếu đúng như dự báo, giá các mặt hàng xăng trong nước vào phiên điều chỉnh giá ngày mai sẽ có đợt giảm đầu tiên sau 5 lần tăng liên tiếp. Còn tính trong vòng 1 năm qua, giá các mặt hàng xăng trong nước được điều chỉnh tăng tới 18 lần, giảm 3 lần và giữ nguyên 3 lần. (Tuấn, 2021a)

\section{Quốc tế:}

- Giá xăng thành phẩm trên thị trường Singapore tính đến ngày 17/11 với xăng RON 92 và RON 95 là 2 hãng xăng chủ yếu giảm 7-8\% so với cùng kỳ năm ngoái và trước đó, giá tiếp tục giảm xuống 93,34 USD và 95,89 USD ( thông tin từ Bộ Công thương Việt Nam) (Hà, 2021)

- Trên sàn Mechanical Fuel của New York, đến đầu giờ sáng 22.11, giá dầu thô tăng nhẹ ( theo WTI), giao tháng 1.2022 đứng ở mức 75,16 USD/thùng, giảm 0,78 USD/thùng trong phiên.

- Còn giá dầu Brent giao tháng 1.2022 đạt ở mức 78,07 USD/thùng, giảm 0,82 USD/thùng.

- Giá xăng dầu thế giới giảm liên tục trong bối cảnh chính quyền Tổng thống Joe Biden tìm

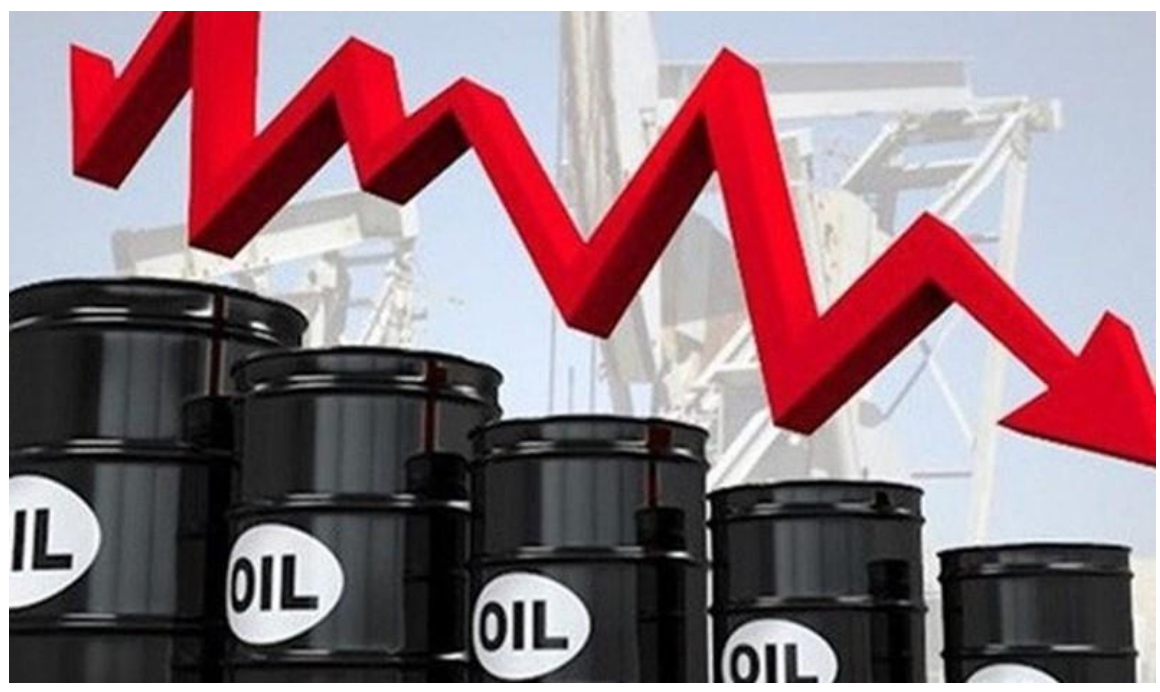


cách kiểm soát giá các mặt hàng nhiên liệu tại Mỹ. Bộ Năng lượng Mỹ được cung cấp dữ liệu từ Nhà Trắng cho thấy xuất 50 triệu thùng dầu từ kho.(Tuấn, 2021b)

\section{Chính sách hỗ trọ giá xăng dầu của chính phủ:}

- Các biện pháp cắt giảm trợ giá và hàm ý chính sách

- Kinh nghiệm quốc tế cho thấy các biện pháp cắt giảm trợ giá xăng dầu nếu muốn thành công phải thực hiện được các mục tiêu sau:

+ Tự do hóa giá các sản phẩm dầu trong nước hoặc thiết lập một công thức điều chỉnh- giá dầu linh hoạt;

+ Đồng thời với các đợt tăng giá là thiết lập các biện pháp giảm thiểu tác động lên người nghèo một cách công khai và nhất thiết phải có các biện pháp có tác động tức thời.(Tuấn, 2021c)

- Phân tích và công khai mặt lợi và mặt hại của hệ thống trợ giá hiện tại;

- Xác định các ưu tiên trong chi tiêu công cộng tại các khu vực tập trung nhiều người nghèo và người có thu nhập trung bình và có thể sử dụng tiết kiệm từ việc bỏ trợ giá để tài trợ cho các chương trình này;

- Thiết lập lộ trình và quy mô tăng giá phù hợp với điều kiện thực tế trong nước và tình hình quốc tế. (BBT, 2012)

- Tuy nhiên, để đạt được những mục tiêu đó, các nước cần phải xác định rõ những khó khăn và những chính sách phù hợp nhằm giải quyết ổn thỏa những vấn đề nảy sinh.

\section{Bảng biểu}

\begin{tabular}{|c|c|c|c|}
\hline Mặt hàng & $\begin{array}{c}\text { Đơn vị tính } \\
\text { (Đã bao gồm thuế } \\
\text { GTGT) }\end{array}$ & Vùng 1 & Vùng 2 \\
\hline Xăng RON 95-IV & Đồng/lít & 17.030 & 17.370 \\
\hline Xăng RON 95-III & Đồng/lít & 16.930 & 17.260 \\
\hline Xăng sinh hoc E5 RON 92-II & Đồng/lít & 15.940 & 16.250 \\
\hline Eiêzen $0,001 S-V$ & Đồng/lít & 12.990 & 13.240 \\
\hline Điêzen $0,05 S-11$ & Đồng/lít & 12.640 & 12.890 \\
\hline Dấu hỏa $2-\mathrm{K}$ & Đồng/lít & 11.550 & 11.780 \\
\hline Mazút No2B $(3,0 \mathrm{~S})$ & Đồng $/ \mathrm{kg}$ & 12.470 & 12.710 \\
\hline Mazút N $2 \mathrm{~B}(3,5 \mathrm{~S})$ & Đô̂ng $/ \mathrm{kg}$ & 12.270 & 12.510 \\
\hline Mazút $180 \mathrm{cst}-0,5 \mathrm{~S}$ (RMG) & Đồng $/ \mathrm{kg}$ & 17.870 & 18.220 \\
\hline
\end{tabular}

(Ghi chú: Mức giá ghi trên là giá bán lẻ, riêng đối với mặt hàng Mazút là giá bán buôn)

Mức giá mói có hiệu lực tù̀ thời điểm 15 giờ 00 ngày 11 tháng 01 năm 2021 (Nguồn: Petrolimex VN)

Giá xăng này sẽ có những thay đổi mới, khi có sự thay đổi sẽ có thông cáo báo chí và trình lên các cơ quan có liên quan để tất cả mọi người được biết. Gía xăng này sẽ áp dụng ở mọi hệ thống phân phối của Petrolimex. (Theo như trang thông báo chính thức của Petrolimex Việt Nam) 
Những giải pháp ứng phó của chính phủ đã có tác động tích cực, tuy nhiên, để giải quyết căn cơ vấn đề an ninh năng lượng (Xăng) thì cần sử dụng hệ xử lý thông tin 3D (Vuong, Q.H., 2022; Vuong \& Napier, 2014). chúng tôi cho rằng nhà nước cần tập trung vào hệ sinh thái giải pháp thay vì cho một giải pháp đơn lẻ. Cụ thể, trước tiên là tập trung vào thông tin truyền thông (loại bỏ kiểm duyệt các thông tin sai lệch), lắng nghe ý kiến chuyên gia trong lĩnh vực năng lượng..., tạo các kênh trao đổi giữa các bên liên quan. Bằng cách này tìm ra được hệ giải pháp sáng tạo giúp đạt được hài hòa các mục tiêu kinh tế, xã hội bền vững.

\section{Tài liệu tham khảo:}

BBT. (2012). Chuyên gia kinh tế Ngô Trí Long: Giá xăng dầu đã được điều hành đúng và quản lý chặt chẽ. Tài Chính Online. https://tapchitaichinh.vn/nghien-cuu-trao-doi/chuyen-giakinh-te-ngo-tri-long-gia-xang-dau-da-duoc-dieu-hanh-dung-va-quan-ly-chat-che-5649.html

Diệp, N. Đ. (2009). Phát triển thị truờng Xăng dầu ở Việt nam. Đại học Kinh tế Quốc dân.

Hà, T. (2021). Giá xăng ngày mai có thể giảm mạnh. Vietnam Express. https://vnexpress.net/giaxang-ngay-mai-co-the-giam-manh-4393412.html

Kevin M. Camp, David Mead, Stephen B. Reed, Christopher Sitter, and D. W. (2021). From the barrel to the pump: the impact of the COVID-19 pandemic on prices for petroleum products. Monthly Labor Review, 1-24. https://doi.org/https://doi.org/10.21916/mlr.2020.24.

La, V. P. et al. (2020). Policy response, social media and science journalism for the sustainability of the public health system amid the COVID-19 outbreak: The vietnam lessons. Sustainability (Switzerland), 12(7). https://doi.org/10.3390/su12072931

Tuấn, A. (2021a). Giá xăng dầu sắp giảm mạnh, người tiêu dùng “ngóng.” Báo Lao Động. https://laodong.vn/kinh-te/gia-xang-dau-sap-giam-manh-nguoi-tieu-dung-ngong-975114.ldo

Tuấn, A. (2021b). Giá xăng dầu thế giới tiếp tục giảm mạnh, giá trong nước thế nào? Báo Lao Động. https://laodong.vn/kinh-te/gia-xang-dau-the-gioi-tiep-tuc-giam-manh-gia-trong-nuocthe-nao-976418.1do

Tuấn, A. (2021c). Giá xăng giảm sâu sau 5 lần tăng liên tiếp. Vietnamnet. https:/vietnamnet.vn/vn/kinh-doanh/thi-truong/gia-xang-giam-sau-5-lan-tang-795666.html

Vuong, Q.H., et al. (2022). Covid-19 vaccines production and societal immunization under the serendipity-mindsponge-3D knowledge management theory and conceptual framework. Humanities \& Social Sciences Communications, 9, 22. Retrieved from: https://www.nature.com/articles/s41599-022-01034-6

Vuong, Q. H., \& Napier, N. K. (2014). Making creativity: the value of multiple filters in the innovation process. International Journal of Transitions and Innovation Systems, 3(4), 294 327. https://doi.org/10.1504/ijtis.2014.068306 